\title{
Insuficiência pancreática exócrina: relato de caso
}

\section{Exocrine pancreatic insufficiency: a case report}

\section{Resumo}

A insuficiência pancreática exócrina (IPE), doença comum principalmente em cães, é causada, usualmente, pela atrofia acinar do pâncreas, seguida de pancreatite crônica e obstrução do ducto pancreático, com consequente secreção inadequada de enzimas pancreáticas. O caso clínico descrito foi observado em um cão, macho, de oito anos de idade, em que o diagnóstico de IPE foi levantado pelo resultado do teste da atividade proteolítica fecal (prova do filme de raio- $x$ ). Até o presente momento, o tratamento instituído com suplementação de enzimas pancreáticas e adequação da dieta propiciou a resolução do quadro clínico.

\section{Abstract}

Exocrine pancreatic insufficiency (EPI), a common disease in dogs, is mainly caused by pancreatic acinar atrophy, followed by chronic pancreatitis and pancreatic duct obstruction, with consequent inadequate secretion of pancreatic enzymes. The present paper is a case report observed in a male eightyear-old dog that had the diagnosis of EPI suggested by the fecal proteolytic activity test (X-ray film proof). To date, the treatment given with pancreatic enzyme supplementation and adequate diet has been able to promote the resolution of the clinical condition. 
Karoline Marcondes Valentim ${ }^{1}$

Maryna Lança Vilia Alberto²

Elis Roberti Perlato do Lago ${ }^{3}$

Jefferson Douglas Soares Alves ${ }^{4}$

Fernanda Leme Silva Bastos Varzim ${ }^{5}$
Av. Dr. Octávio da Silva Bastos, s/n., São João da Boa Vista/SP

CEP:13874-159

的arolinevalentim.vet@gmail.com
Palavras-chave: Cães.

Enzimas pancreáticas.

IPE. Tripsina fecal.

Keywords: Dog. Pancreatic enzymes.

EPI. Fecal trypsin.

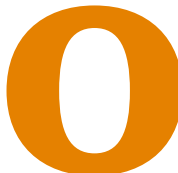

presente trabalho apresenta uma revisão dos métodos de diagnóstico da insuficiência pancreática exócrina e relata um caso observado em um paciente atendido no Hospital Veterinário do Centro Universitário Otávio Bastos (UNIFEOB).

O pâncreas é dividido em duas partes, a porção endócrina e a exócrina, com um único estroma. Com isso, os problemas inflamatórios que acometem uma dessas porções podem afetar a outra (VERSANNIO, 2011; CONCEIÇÃO, 2013). A porção exócrina do pâncreas é organizada em ácinos e as células acinares são as responsáveis pela secreção de enzimas responsáveis pela digestão de carboidratos, proteínas e lipídios (CARVALHO; SILVA; SILVA, 2010; ALMEIDA et al., 2011; VERSANNIO, 2011; PINZON; CURIN; MARTINS, 2012; SANTANA et al., 2014; ALLISON, 2015).

O pâncreas exócrino possui uma considerável reserva funcional de enzimas, mas quando ele perde sua capacidade secretora enzimática ocorrem sinais de má digestão que caracterizam um processo degenerativo denominado de insuficiência pancreática exócrina (IPE) (WIBERG; NURMI; WESTERMARCK, 1999; WIBERG; SAARI; WESTERMARCK, 1999; STEINER; WILLIAMS, 2000; BATCHELOR et al., 2007a; CARVALHO; SILVA; SILVA, 2010;

${ }^{1}$ Médica-veterinária aprimoranda na área de Patologia Clínica do Hospital Veterinário do Centro Universitário da Fundação de Ensino Octávio Bastos. ${ }^{2}$ Médica-veterinária aprimoranda na área de Clínica e Cirurgia de Pequenos do Hospital Veterinário do Centro Universitário da Fundação de Ensino Octávio Bastos.

${ }^{3}$ Médica-veterinária aprimoranda na área de Diagnóstico por Imagem do Hospital Veterinário do Centro Universitário da Fundação de Ensino Octávio Bastos.

${ }^{4}$ Professor mestre da disciplina de Diagnóstico por Imagem do Curso de Medicina Veterinária da UNIFEOB e FAJ.

${ }^{5}$ Professora mestre da disciplina de Patologia Clínica do Curso de Medicina Veterinária da UNIFEOB. 
WESTERMARCK; SAARI; WIBERG, 2010; ALMEIDA et al., 2011; MATILDE et al., 2011; VERSANNIO, 2011; PINZON; CURIN; MARTINS, 2012; CONCEIÇÃO, 2013; SANTANA et al., 2014; ALLISON, 2015).

A IPE geralmente é a consequência de uma grave redução da massa pancreática, ocasionada frequentemente por: a) atrofia acinar pancreática (AAP) (WIBERG; NURMI; WESTERMARCK, 1999; WIBERG; SAARI; WESTERMACK, 1999; BATCHELOR et al., 2007a; CARVALHO; SILVA; SILVA, 2010; WESTERMARCK; SAARI; WIBERG, 2010; MATILDE et al., 2011; VERSANNIO, 2011; PINZON; CURIN; MARTINS, 2012; CONCEIÇÃO, 2013; SANTANA et al., 2014); b) pancreatite crônica; (WIBERG; SAARI; WESTERMARCK, 1999; STEINER; WILLIAMS, 2000; CARVALHO; SILVA; SILVA, 2010; ALMEIDA et al., 2011; MUÑOZ, 2011; CONCEIÇÃO, 2013; SANTANA et al., 2014) ou c) obstrução do ducto pancreático (SANTANA et al., 2014). Também pode ocorrer em razão de: a) episódios recorrentes de pancreatite aguda ou subaguda; b) desnutrição proteica grave (CARVALHO; SILVA; SILVA, 2010; VERSANNIO, 2011; PINZON; CURIN; MARTINS, 2012); c) hipoplasia do pâncreas (BATCHELOR et al., 2007a; ALMEIDA et al., 2011; VERSANNIO, 2011); d) fibrose cística; e) doença celíaca; f) inativação mediada por ácido de enzimas pancreáticas (síndrome de Zollinger-Ellison); g) gastrectomia ou duodenopancreatectomia (MUÑOZ, 2011); ou ainda h) neoplasia (BATCHELOR et al., 2007a; ALMEIDA et al., 2011; MUÑOZ, 2011; CONCEIÇÃO, 2013). A secreção excessiva de suco gástrico (VERSANNIO, 2011) e a diabetes mellitus são outros fatores que diminuem a atividade das enzimas pancreáticas e que podem ocasionar a redução da massa pancreática (VERSANNIO, 2011; CONCEIÇÃO, 2013).

Os sintomas mais comuns da IPE são diarreia com fezes volumosas, semiformadas, amareladas ou cinzentas, esteatorreia, polifagia, perda de peso, borborigmos intestinais, flatulência e problemas dermatológicos (WIBERG; NURMI; WESTERMARCK, 1999; STEINER; WILLIAMS, 2000; BATCHELOR et al., 2007a; BATCHELOR et al., 2007b; CARVALHO; SILVA; SILVA, 2010; WESTERMARCK; SAARI; WIBERG, 2010; ALMEIDA et al., 2011; MATILDE et al., 2011; MUÑOZ, 2011; VERSANNIO, 2011; PINZON; CURIN; MARTINS, 2012; SANTANA et al., 2014). Versannio (2011) e Pinzon, Curin e Martins (2012) relataram que também podem ser observados o apetite depravado e a coprofagia. O crescimento bacteriano no intestino delgado pode ser uma ocorrência secundária à IPE, consequente à perda de fatores bacteriostáticos normalmente presentes no suco pancreático (BATCHELOR et al., 2007b).

Os sinais clínicos observados na IPE são determinados pela má absorção de nutrientes, decorrente da digestão intraluminal (WIBERG; NURMI; WESTERMARCK, 1999; STEINER; WILLIAMS, 2000; CARVALHO; SILVA; SILVA, 2010; MUÑOZ, 2011; VERSANNIO, 2011). Destaque-se também que as causas infecciosas, parasitárias, metabólicas e anatômicas de diarreia do intestino delgado devem ser descartadas (MATILDE et al., 2011; CONCEIÇÃO, 2013).

$\mathrm{Na}$ IPE, as alterações secundárias da mucosa intestinal, representadas por atrofia das vilosidades, infiltrado de células inflamatórias e alterações na atividade enzimática da mucosa contribuem para a má absorção (PINZON; CURIN; MARTINS, 2012).

Estudos sobre a patologia da IPE geralmente foram baseados na fase clínica da doença. Porém, quando os sinais clínicos aparecem, a porção exócrina do pâncreas já está praticamente destruída e fornece pouca informação sobre a patogênese da doença (WIBERG et al., 1999b).

$\mathrm{O}$ diagnóstico da disfunção pancreática exócrina baseia-se nos sinais clínicos e é confirmado com o emprego dos testes de função pancreática (BATCHELOR et al., 2007a; CARVALHO; SILVA; SILVA, 2010; MATILDE et al., 2011; CONCEIÇÃO, 2013).

Os exames laboratoriais de rotina, como hemograma completo, bioquímica sérica e, urinálise geralmente encontram-se dentro dos padrões de normalidade (CARVALHO; SILVA; SILVA, 2010; MATILDE et al., 2011; VERSANNIO, 2011; ALLISON, 2015). Em alguns casos onde já há dano hepático secundário, a alanina aminotransferase (ALT) e a fosfatase alcalina (FA) podem ser encontradas levemente aumentadas (STEINER; WILLIAMS, 2000; CARVALHO; SILVA; SILVA, 2010; VERSANNIO, 2011).

A amilase e a lipase sanguíneas podem estar normais ou levemente reduzidas, mas esses parâmetros não são usados para o diagnóstico definitivo de IPE, uma vez que essas enzimas também são produzidas em outros órgãos (CARVALHO; SILVA; SILVA, 2010; ALLISON, 2015).

Diversos testes de função pancreática têm se mostrado úteis em confirmar a IPE. O teste de imunorreatividade semelhante à tripsina sérica (TLI) é o mais sensível e específico em se tratando de atividade pancreática (WIBERG; NURMI; WESTERMARCK, 1999; STEINER; WILLIAMS, 2000; BATCHELOR et al., 2007a; CARVALHO; SILVA; SILVA, 2010; MATILDE et al., 2011; PINZON; CURIN; MARTINS, 2012; CONCEIÇÃO, 2013; SANTANA et al., 2014; ALLISON, 2015), pois permite um diagnóstico diferencial entre IPE e doenças do intestino delgado (CARVALHO; SILVA; SILVA, 2010). 
Foi comprovado que baixos níveis séricos persistentes de TLI já ocorrem antes mesmo das manifestações clínicas, fornecendo um diagnóstico precoce da forma clínica da doença, embora já estejam presentes alterações macroscópicas no pâncreas, tais como diminuição da massa pancreática e atrofia (WIBERG; SAARI; WESTERMARCK, 1999).

A avaliação da atividade proteolítica fecal com o emprego do teste de digestão do filme raio-x é um método simples e prático de ser realizado na rotina clínica. Esse teste detecta a presença de enzimas pancreáticas nas fezes, mas, por conta das variações fisiológicas diárias que podem ocorrer em pacientes saudáveis e que reduzem a atividade proteolítica, para que não ocorram resultados falso-positivos, a atividade deve ser mensurada em mais de uma amostra (CARVALHO; SILVA; SILVA, 2010; VERSANNIO, 2011; PINZON; CURIN; MARTINS, 2012; CONCEIÇÃO, 2013). O ideal é que o registro seja obtido em três dias consecutivos (STEINER; WILLIAMS, 2000). Em cada observação devem ser examinados três tipos de amostras: a) sem fezes, controle negativo; b) fezes de animal sadio, controle positivo; e c) fezes do animal a ser testado (VERSANNIO, 2011; PINZON; CURIN; MARTINS, 2012).

Uma das formas de identificação da pancreatite como etiologia da IPE é com a utilização de um teste rápido, chamado SNAP ${ }^{\circledast}$ cPLTM (IDEXX Laboratories), que é um teste espécie-específico que determina a concentração sérica da lipase pancreática canina (cPLI) originada nos ácinos pancreáticos (CONCEIÇÃO, 2013).

A confirmação e a definição da etiologia da IPE podem ser obtidas por meio de exame histopatológico (ALMEIDA et al., 2011; CONCEIÇÃO, 2013).

A biópsia pancreática pode mostrar achados histopatológicos de fibrose, atrofia, falta de tecido acinar ou grânulos de zimogênio dentro das células acinares. Entretanto, na maioria dos casos não se pode estimar a quantidade de tecido acinar funcional (STEINER; WILLIAMS, 2000).

Outros exames que podem ser realizados são: teste de digestão de bentiromida oral, microscopia fecal, medição de folato (VERSANNIO, 2011) e cobalamina séricos (VERSANNIO, 2011; CONCEIÇÃO, 2013).

Na ultrassonografia, podem ser observados diminuição no tamanho do pâncreas, graus de ecogenicidade variáveis do parênquima pancreático, ecotextura nodular, sombra acústica devido à mineralização e fibrose e dilatação irregular dos ductos pancreáticos que definem a pancreatite crônica. A ultrassonografia também pode acusar a presença de nódulo ou massa pancreática ou peripancreática de variados tamanhos e ecogenicidade (CONCEIÇÃO, 2013).
Atualmente, quando não há sinais clínicos da doença, nenhum tratamento é recomendado (WESTERMARCK; SAARI; WIBERG, 2010). Havendo sintomatologia, o tratamento da IPE baseia-se na suplementação com enzimas pancreáticas (BATCHELOR et al., 2007b; CARVALHO; SILVA; SILVA, 2010; MATILDE et al., 2011; MUÑOZ, 2011; VERSANNIO, 2011; CONCEIÇÃO, 2013; SANTANA et al., 2014), que se encontra disponível em forma de cápsula (Creon 25.000: 1 cáp./ BID - 20 minutos antes das refeições, por toda vida), (CARVALHO; SILVA; SILVA, 2010; VERSANNIO, 2011; SANTANA et al., 2014) e na modificação da dieta para uma que tenha maior digestibilidade e baixos teores de gordura e fibras (BATCHELOR et al., 2007b; CARVALHO; SILVA; SILVA, 2010; MATILDE et al., 2011; MUÑOZ, 2011; VERSANNIO, 2011; CONCEIÇÃO, 2013; SANTANA et al., 2014).

Devido à má absorção de vitaminas e minerais, pode-se também fazer a suplementação com vitaminas A, E, K e B12 e zinco (BATCHELOR et al., 2007b; CARVALHO; SILVA; SILVA, 2010; MATILDE et al., 2011; PINZON; CURIN; MARTINS, 2012; CONCEIÇÃO, 2013; SANTANA et al., 2014).

Caso não haja resposta satisfatória ao tratamento, deve ser avaliada a possibilidade de erro no diagnóstico ou ainda erro na dosagem enzimática (CARVALHO; SILVA; SILVA, 2010).

O prognóstico da IPE dependerá do estado geral do animal, da resposta ao tratamento e da etiologia (CONCEIÇÃO, 2013).

A diarreia e a esteatorreia são sinais clínicos que podem persistir em cães com IPE, apesar do tratamento efetuado. Além disso, após um ano de tratamento, a despeito da normalização do apetite, alguns animais podem continuar abaixo do peso (BATCHELOR et al., 2007b; MATILDE et al., 2011).

\section{Relato de caso}

Foi atendido no Hospital Veterinário Vicente Borelli, da UNIFEOB, no município de São João da Boa Vista/ SP, um canino, macho, sem raça definida, de oito anos e nove meses de idade, pesando $11 \mathrm{~kg}$ e sem vacinas em dia, que se alimentava da ração de nome comercial Pedigree ${ }^{\star}$ Carne e Vegetais Adulto, à vontade, composto por farinha de carne e ossos, farinha de subprodutos de frango, milho integral moído, gordura de frango, farelo de milho, cenoura, espinafre, metionina, triptofano, vitaminas (a, d3, e, b1, b2, b6, b12, niacina, ácido pantotênico, ácido fólico, biotina e cloreto de colina), minerais (cloreto de sódio, óxido de zinco, cloreto de potássio, sulfato de 
cobre, sulfato de ferro, iodato de cálcio e selenito de sódio), hidrolisado de fígado de ave e suíno, bht e corantes (caramelo, azul indigotina, amarelo tartrazina e amarelo crepúsculo). Eventuais substitutivos: sorgo integral moído, quirera de arroz, glúten de milho, farelo de trigo, farelo de soja, proteína concentrada de soja e óleo de soja refinado. A quantidade do alimento indicada para as raças médias (peso vivo de 10 a 25kg) era ingestão de 155 a 305 gramas por dia. Apresentava como queixa principal polifagia, polidipsia, emagrecimento progressivo há seis meses, grande volume fecal de consistência pastosa com presença de alimentos não digeridos (Figura 1).

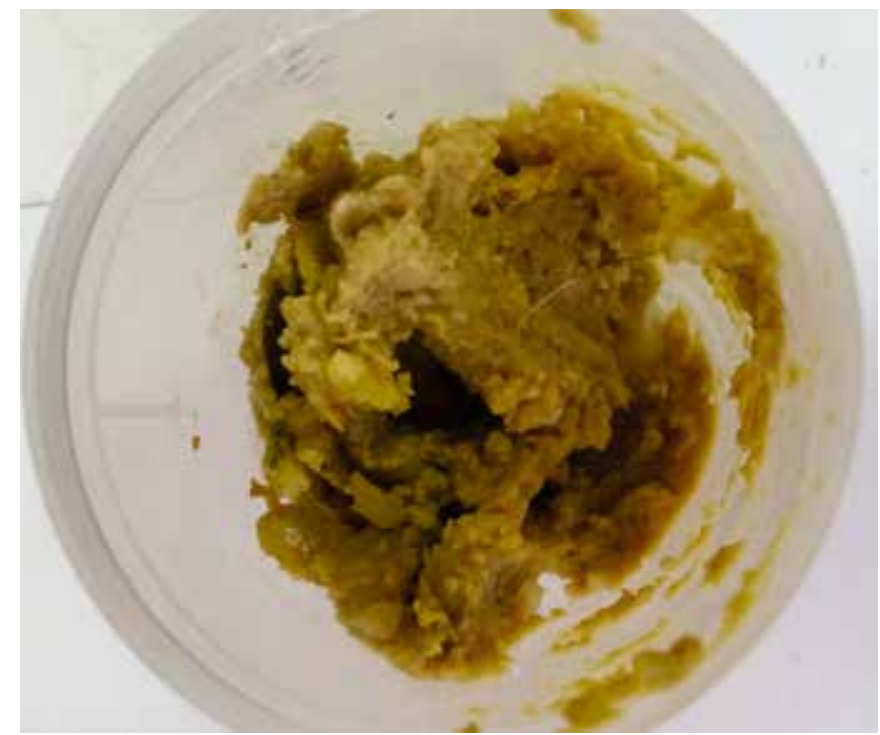

Figura 1. Exame macroscópico das fezes evidenciando presença de alimento não digerido (círculos).

Fonte: Arquivo pessoal (2015).

Apesar de estar em tratamento com fenobarbital (100mg, meio comprimido SID), continuou apresentando episódios convulsivos. Foi tratado previamente por outro médico-veterinário, para giardíase, hemoparasitoses, gastroenterite alimentar e insuficiência renal crônica (IRC), sem sucesso. Ao exame físico apresentou-se deprimido, caquético, ictérico, levemente desidratado, bradicárdico, arrítmico e com urina levemente turva e escura.

Após avaliação clínica, foram solicitados exames complementares na tentativa de diferenciar o diagnóstico entre hiperadrenocorticismo, síndrome de má absorção, pancreatite crônica e IPE, hepatopatia ou IRC. Foi realizado hemograma completo, bioquímico sérico (ureia, creatinina, ALT e FA, ultrassonografia abdominal, coproparasitológico e o teste para avaliação da atividade proteolítica fecal, por meio do teste de digestão do filme de raio-x. No hemograma foram observadas trombocitose e eosinofilia, no bioquímico sérico foram constatadas alterações nas enzimas hepáticas e no coproparasitológico foi observada a presença de gotículas de gordura (Figura 2). O exame ultrassonográfico apresentou resultados dentro dos padrões de normalidade e o teste do filme de raio-x foi negativo para presença de atividade da enzima tripsina fecal nas amostras testadas em três dias consecutivos. Dessa maneira, o diagnóstico sugerido foi a IPE (Figuras 3A e 3B).

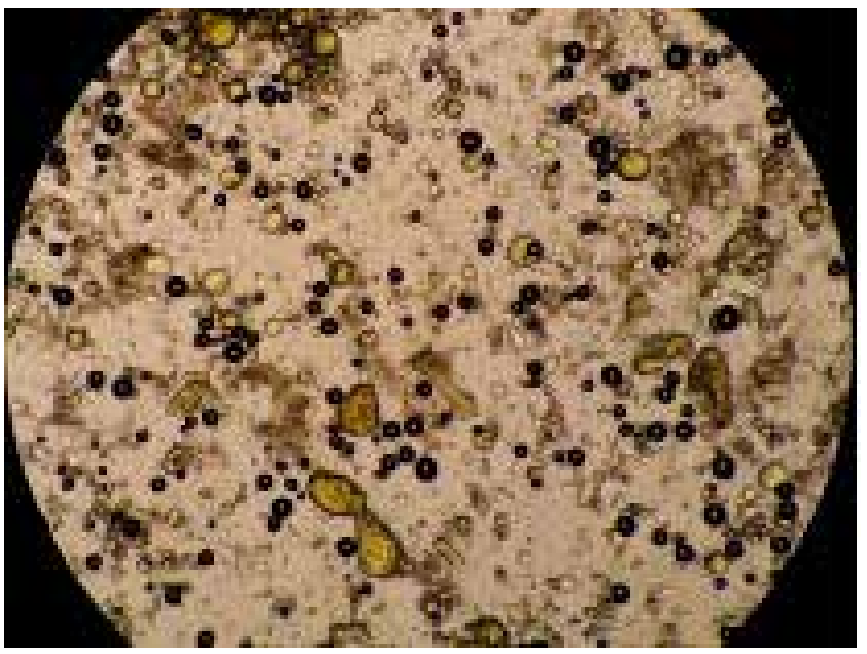

Figura 2. Exame microscópico das fezes evidenciando gotículas de gordura (setas).

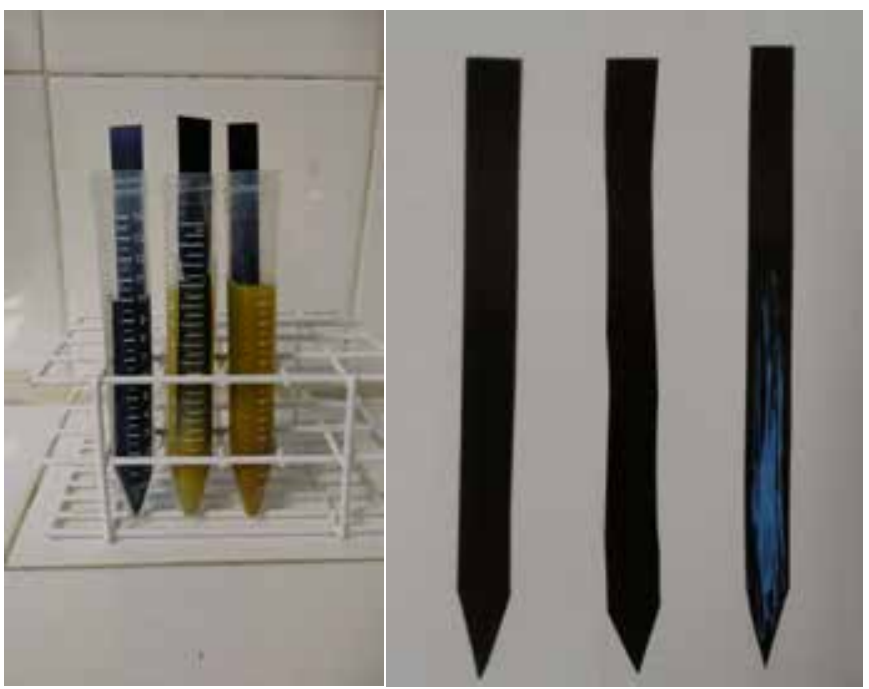

Figura 3A. Teste do filme de RX. 3B. Resultado: 1- sem fezes (controle negativo), 2-fezes teste (fezes do animal testado), indicando a ausência de enzimas digestivas, e 3- fezes do animal sadio (controle positivo), filme digerido.

Fonte: Arquivo pessoal (2015).

A partir dos resultados obtidos foi instituído o tratamento com Fenobarbital 100mg / meio comprimido / BID / contínuo; Pancreatina dois comprimidos / QID / contínuo / 20 minutos antes da alimentação associado à Ranitidina $2 \mathrm{mg} / \mathrm{Kg}$; complexo vitamínico, um comprimido / SID / 30 dias, que auxilia no metabolismo de 
gorduras e proteínas. Além disso, a dieta foi alterada para a ração da marca Hills ${ }^{\circledR}$ Estômago Sensível, oferecida quantidade indicada pelo fabricante de acordo com o peso do animal, dividida em refeições quatro vezes ao dia, composta por arroz moído (min 18\% de arroz), milho moído, farinha de aves (min. 20\% frango), glúten de milho, secos (min. 13\% de ovo), gordura animal, hidrolisado, óleo vegetal, semente de linhaça, fibra de aveia, beterraba seca celulose, cloreto de potássio, cloreto de sódio, cloridrato de L-lisina, L-triptofano, vitaminas e oligoelementos. Naturalmente conservada com tocoferóis mistos, ácido cítrico e extrato de alecrim, além dos aditivos nutricionais Vitamina A [E 672] $(16.000 \mathrm{IU} / \mathrm{kg})$, vitamina D3 [E 671] (941 UI / kg), ferro [E1] (68,2mg / $\mathrm{kg})$, iodo [E2] (1,1mg / kg), cobre [E4] $(6,7 \mathrm{mg} / \mathrm{kg})$, manganês [E5] (7,1mg / kg), zinco [E6] (141mg / kg), selénio [E8] $(0,2 \mathrm{mg} / \mathrm{kg})$. A recomendação de ingestão diária é de 145 a $335 \mathrm{~g} /$ dia para animais entre $10-20 \mathrm{~kg}$.

Um mês após o início do tratamento, o paciente foi reavaliado, sendo constatado que os parâmetros vitais estavam normais, embora apresentasse leve arritmia, aumento de peso para $12,7 \mathrm{~kg}$, normofagia e ausência de alimentos não digeridos nas fezes.

Decorridos três meses de tratamento, $\mathrm{o}$ animal retornou pesando 14,7kg (Figurras 4A e 4B), com todos os parâmetros normais, e continuou com alterações em ALT e FA, sem relatos de crises convulsivas.

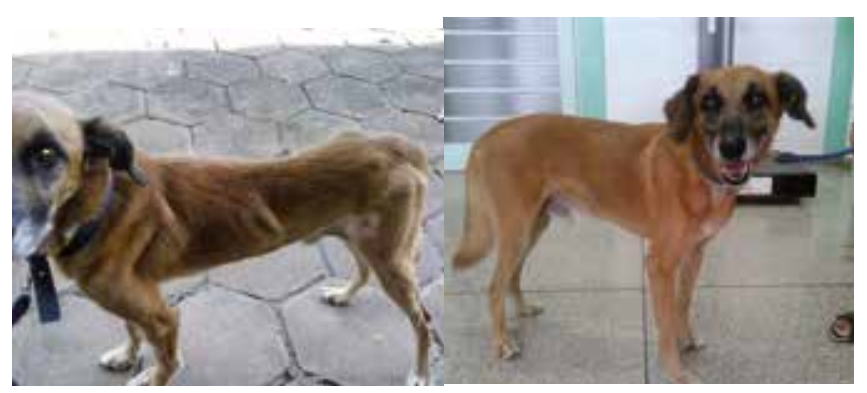

Figura 4. Ody. A- antes e B- após três meses de tratamento. Fonte: Arquivo pessoal (2015)

\section{Discussão}

O animal relatado apresentava polifagia, polidipsia, emagrecimento progressivo, grande volume fecal com consistência pastosa e coloração amarela com presença de alimentos não digeridos, sinais compatíveis com a IPE (WIBERG; NURMI; WESTERMARCK, 1999; STEINER; WILLIAMS, 2000; BATCHELOR et al., 2007a; BATCHELOR et al., 2007b; CARVALHO; SILVA; SILVA, 2010; WESTERMARCK; SAARI; WIBERG, 2010; ALMEIDA et al., 2011; MUÑOZ, 2011; MATILDE et al., 2011; VERSANNIO, 2011; PINZON; CURIN; MARTINS, 2015; SANTANA et al., 2014).

Optou-se, então, por fazer de início os exames de rotina como hemograma, bioquímico (ureia, creatinina, ALT e FA), coproparasitológico e ultrassonografia. Como a principal suspeita era a IPE, e o proprietário não se dispôs a fazer exames mais específicos, o método de escolha foi o teste para avaliar a atividade proteolítica fecal (prova do filme de raio-X), sendo este o mais prático e rápido (CARVALHO; SILVA; SILVA, 2010; VERSANNIO, 2011; PINZON; CURIN; MARTINS, 2012; CONCEIÇÃO, 2013).

O teste foi realizado em três dias consecutivos, e o resultado obtido foi negativo para digestão do filme, direcionando o diagnóstico para IPE (STEINER; WILLIAMS, 2000).

Apesar de exames laboratoriais, como hemograma e bioquímico sérico (ALT e FA), serem descritos em literatura dentro dos valores normais (CARVALHO; SILVA; SILVA, 2010; MATILDE et al., 2011; VERSANNIO, 2011; ALLISON, 2015), no presente caso foram observadas alterações como trombocitose e eosinofilia, e elevações das enzimas hepáticas (STEINER; WILLIAMS, 2000; CARVALHO; SILVA; SILVA, 2010; VERSANNIO, 2011).

Até o presente momento o tratamento instituído com suplementação enzimática (BATCHELOR et al., 2007b; CARVALHO; SILVA; SILVA, 2010; MATILDE et al., 2011; MUÑOZ, 2011; VERSANNIO, 2011; CONCEIÇÃO, 2013; SANTANA et al., 2014) e modificação da alimentação para o emprego de uma ração com baixo teor de gorduras (BATCHELOR et al., 2007b; CARVALHO et al., 2010; MATILDE et al., 2011; MUÑOZ, 2011; VERSANNIO, 2011; CONCEIÇÃO, 2013; SANTANA et al., 2014) foi efetivo, permitindo a qualidade de vida ao animal com IPE; contudo, alguns autores acreditam que $\mathrm{o}$ alto teor de gorduras possa promover o ganho de peso (BATCHELOR et al., 2007b; CARVALHO; SILVA; SILVA, 2010; MUÑOZ, 2011).

\section{Conclusão}

Apesar de ser uma doença que acomete geralmente cães da raça Pastor Alemão, a IPE não deve ser descartada do diagnóstico diferencial dos demais animais. A avaliação da atividade proteolítica fecal por meio da digestão do filme de raio-x é um método simples, prático e econômico que permite a análise da atividade das enzimas pancreáticas nas fezes; apesar de não ser considerado como o teste mais sensível e específico para IPE, no presente caso, considerando os sinais clínicos apresentados e a melhora do animal após a instituição do tratamento, o emprego do teste foi considerado satisfatório. () 


\section{Referências}

ALLISON, R. W. Avaliação laboratorial do pâncreas e metabolismo da glicose. In: THRALL, M. A. et al. Hematologia e bioquímica clínica veterinária. 2. ed. São Paulo: Roca, 2015. cap. 27, p. 367-380.

ALMEIDA, P. R. et al. Descrição de quatro casos de atrofia do pâncreas exócrino em cães. Acta Scientiae Veterinariae, Porto Alegre, v. 39, n. 3, p. 1-5, 2011.

BATCHELOR, D. J. et al. Breed associations for canine exocrine pancreatic insufficiency. Journal of Veterinary Internal Medicine, Hoboken, v. 21, n. 2, p. 207-214, Mar.-Apr. 2007a.

D. J. et al. Prognostic factors in canine exocrine pancreatic insufficiency: prolonged survival is likely if clinical remission is achieved. Journal of Veterinary Internal Medicine, Hoboken, v. 21, n. 1, p. 54-60, Jan.-Feb. 2007b.

CARVALHO, C. F.; SILVA, E. B.; SILVA, L. C. S. Insuficiência Pancreática Exócrina em um cão da raça Cocker Spaniel Inglês: relato de caso. Ambiência Guarapuava, Guarapuava, v. 6, n. 3, p. 523-527, set./dez. 2010

CONCEIÇÃO, N. F. Insuficiência pancreática exócrina em cães: métodos diagnósticos e alternativas terapêuticas - revisão de literatura. 2011. 78 f. Trabalho de Conclusão de Curso (Graduação) - Faculdade de Agronomia e Medicina Veterinária, Universidade de Brasília, Brasília, 2013.

MATILDE, K. S. et al. Importância da imunorreatividade semelhante à tripsina sérica (IST) no diagnóstico definitivo da insuficiência pancreática exócrina: relato de caso. Revista de Educação Continuada em Medicina Veterinária e Zootecnia, São Paulo, v. 9, n. 2, p. 38-40, 2011.

MUÑOZ, J. E. D. Pancreatic exocrine insufficiency: diagnosis and treatment. Journal of Gastroenterology and Hepatology, Melbourne, v. 26, n. 2, p. 12-16, Mar. 2011.

PINZON, P. W.; CURIN, L.; MARTINS, D. B. Insuficiência pancreática exócrina em cães: revisão bibliográfica. In: SEMINÁRIO INTERINSTITUCIONAL DE ENSINO, PESQUISA E EXTENSÃO, 17.; MOSTRA DE INICIAÇÃO CIENTÍFICA, 15.; MOSTRA DE EXTENSÃO, 10., 2012, Cruz Alta. Anais eletrônicos... Cruz Alta: Unicruz, 2012. Disponível em: <http://www.unicruz.edu.br/seminario/downloads/anais/ccs/insuficiencia\% 20 pancreatica $\% 20$ exocrina $\% 20 \mathrm{em} \% 20$ caes $\% 20$ revisao\%20bibliografica.pdf>. Acesso em: 5 nov. 2015.

SANTANA, A. D. et al. Insuficiência pancreática exócrina em um cão SRD: relato de caso. Enciclopédia Biosfera, Goiânia, v. 10, n. 18, p. 2046-2053, 2014.

STEINER, J. M.; WILLIAMS, D. A. Serum feline trypsin-like immunoreactivity in cats with exocrine pancreatic insufficiency. Journal of Veterinary Internal Medicine, Lakewood, $v$. 14, n. 6, p. 627-629, Nov.-Dec. 2000.

VERSANNIO, C. C. Insuficiência pancreática exócrina em cães. 2011. 17 p. Tese (PósGraduação) - Universidade Castelo Branco, São Paulo, 2011.

WESTERMARCK, E.; SAARI, S. A. M.; WIBERG, M. E. Heritability of exocrine pancreatic insufficiency in German shepherd dogs. Journal of Veterinary Internal Medicine, Lakewood, v. 24, n. 2, p. 450-452, Mar.-Apr. 2010.

Serum trypsinlike immunoreactivity measurement for the diagnosis of subclinical exocrine pancreatic insufficiency. Journal of Veterinary Internal Medicine, Lakewood, $v$. 13, n. 5, p. 426-432, Sept.-Oct. 1999.

WIBERG, M. E.; SAARI, S. A. M.; WESTERMARCK, E. Exocrine pancreatic atrophy in German shepherd dogs and rough-coated collies: an end result of lymphocytic pancreatitis. Veterinary Pathology, Lawrence, v. 36, n. 6, p. 530-541, Nov. 1999 